\title{
Class Attendance and the Performances in Physiology Board Examinations: A Study in a Caribbean Medical School
}

\author{
Raju Panta*, Frances Jack-Edwards and Mignonette Relatado-Sotto \\ Trinity School of Medicine, St. Vincent and the Grenadines, West Indies
}

Submission: February 19, 2017; Published: March 03, 2017

*Corresponding author: Raju Panta, Department of Physiology, Trinity School of Medicine, St. Vincent and the Grenadines, West Indies, Email: tsomdesk.rp@gmail.com

\section{Abstract}

Objective: Many faculty members in medical schools encourage their students to attend classes regularly emphasizing that some studies have reported strong positive correlation between the performances in the National Board of Medical Examiners (NBME) examination with their class attendance. The objective of our study was to assess the association of the physiology class attendance and NBME physiology scaled score.

Methods: For this study, 93 medical students who completed two terms of medical physiology at Trinity School of Medicine (TSOM) were selected. They had their first attempt of NBME physiology examination from summer 2014 to fall 2015. Their physiology class attendance and NBME physiology scaled score were tabulated in Microsoft Excel. The correlation of the percentage of physiology class attendance and NBME physiology scaled score was determined by a Pearson correlation coefficient and regression analysis, using the SPSS version 24.

Results: The class attendance was a significant predictor of performance in physiology NBME subject examination $\left(\mathrm{R}^{2}{ }_{(91)}=0.295, \mathrm{p}=\right.$ $.000)$. A significant positive correlation was found between the class attendance (\%) and NBME physiology score $\left(\mathrm{r}_{(91)}=.543, \mathrm{p}<0.001\right)$.

Conclusion: The class attendance (\%) was significantly correlated with the NBME physiology score. The physiology class attendance appears to be related to NBME physiology scaled score. However, the impacts of other factors such as study habits, environment, cultural habits, gender difference, and personal, familial, and socioeconomic stresses need to be assessed in further studies.

Keywords: NBME; Physiology; Scaled Scores; Class Attendance; Caribbean Medical School

Abbreviations: NBME: National Board of Medical Examiners; TSOM: Trinity School of Medicine; SAT: Scholastic Assessment Test; HSGPA High School Grade Point Average; USMLE: United States Medical Licensing Examination

\section{Introduction}

Many faculty members in medical schools encourage their students to attend classes regularly emphasizing that regular class attendance facilitates learning and enhances their performance in examinations. Class attendance appears to be a better predictor of college grades than any other known predictor of college grades - including Scholastic Assessment Test (SAT) scores, High School Grade Point Average (HSGPA), studying skills, and the amount of time spent studying [1]. The efforts to increase the class attendance rates among college students helped to achieve dramatic improvements in average grades [2].

The National Board of Medical Examiners (NBME) provides subject examinations in the basic and clinical sciences to medical schools and other institutions that educate physicians or other health professionals. The NBME subject examinations assess the educational achievement of medical students in specific subject areas. These examinations are used at virtually all allopathic medical schools and many osteopathic medical schools in the United States and Canada, and approximately 25 international schools in the Caribbean, Mexico, Europe, Middle East, and Asia. The NBME examinations are primarily used as final examinations after courses, clerkships, or other units of instruction. However, the scores achieved on NBME examinations cannot be used by examinees for credit toward the United States Medical Licensing Examination (USMLE) [3]. Some studies reported that the NBME performance has a strong positive correlation with the class attendance [4-6]. Hence, we 
aimed to assess the correlation of physiology class attendance (\%) with the NBME physiology scaled score.

\section{Material and Methods}

The present study is an analytical comparative study. The study was conducted in Trinity School of Medicine (TSOM), St. Vincent and the Grenadines, West Indies. At Trinity, Medical Physiology is taught to students in their first and second terms each of which comprises 15 weeks. The two terms of medical physiology are designed to give the students sufficient mastery over basic physiology and its application in clinical contexts to prepare them for the physiology sections of the USMLE Step 1. The students take part in NBME physiology at the end of their second term.

The medical students who studied two terms of medical physiology and took their NBME physiology subject examination from summer 2014 to fall 2015 at TSOM were included into this study. The students who dropped their physiology course before taking the NBME physiology and continued the same next term, those who did not study their two terms of medical physiology at TSOM, those transferred from other schools to TSOM, and those with low levels of attendance due to medical leave of absence and other extenuating circumstances were excluded from the study. Ethical clearance for the study was obtained from the research ethical committee of TSOM.

Three physiology faculty members utilized sign-in sheets, which were passed out in each class period to record the class attendance. Students were informed that the class attendance was being recorded for informational purposes and that there were no consequences regarding their absences. The students' cooperation was good. At the end of the second term, their first attempt of NBME physiology scaled score and class attendance were tabulated in the Microsoft Excel. The correlation between the class attendance and NBME physiology scaled score was determined by a Pearson correlation coefficient and regression analysis, using the SPSS version 24. A p value of 0.05 or less was considered as statistically significant.

Results

A total of 93 students were included into the study of whom 42 were female and 51 were male. The students' physiology

Table 3: Summary Output of Linear Regression Analysis.

\begin{tabular}{|c|c|c|c|c|c|}
\hline & Coefficients & $\begin{array}{c}\text { Standard } \\
\text { Error }\end{array}$ & t Stat & P-value & Lower 95\% \\
\hline Intercept & 10.423 & 5.818 & 1.792 & 0.077 \\
\hline $\begin{array}{c}\text { Attendance } \\
(\%)\end{array}$ & 0.417 & 0.068 & 6.164 & 0.000 \\
\hline
\end{tabular}

class attendance was measured by the overall attendance percent $($ mean $=85.1 \%, \mathrm{SD}=11.9 \%)$ (Table 1$)$. The students' performance was assessed by the NBME physiology scaled score (mean $=45.9, \mathrm{SD}=9.1)($ Table 1$)$. There was wide variation in the class attendance (\%) and NBME physiology scaled score of individual students.

The correlation coefficient (adjusted $\mathrm{r}^{2}$ ) of our study was 0.287 (Table 2) and significance $F$ was $<0.001$. A significant positive correlation was found between the class attendance $(\%)$ and NBME physiology scaled score $\left(\mathrm{r}_{(91)}=.543, \mathrm{p}<0.001\right)$ (Table 2). The regression model significantly predicted $29.5 \%$ $\left(R^{2}=0.295\right)$ of the NBME physiology scaled score of the students (Table 2).

Table 1: Summary of the Parameters Recorded.

\begin{tabular}{|c|c|c|c|c|}
\hline Variables & Minimum & Maximum & Mean & SD \\
\hline $\begin{array}{c}\text { Class } \\
\text { attendance } \\
\text { (\%) }\end{array}$ & 34.5 & 98.2 & 85.1 & 11.9 \\
\hline $\begin{array}{c}\text { NBME } \\
\text { Scaled } \\
\text { Score }\end{array}$ & 27 & 67 & 45.9 & 9.1 \\
\hline
\end{tabular}

Table 2: Regression Statistics.

\begin{tabular}{|c|c|}
\hline Multiple R & 0.543 \\
\hline R Square & 0.295 \\
\hline Adjusted R Square & 0.287 \\
\hline Standard Error & 7.725 \\
\hline Observations & 93 \\
\hline
\end{tabular}

Simple linear regression analysis between the class attendance (\%) and NBME physiology scaled score showed that the class attendance contributed $26.9 \%$ (confidence interval $0.283,0.552$ ) of the variation in NBME physiology scaled score (Table 3). The regression model showed that for each $1.0 \%$ increase in class attendance, the NBME physiology scaled score is expected to increase by 0.417 (Table 3 ). The equation obtained from the regression model is: NBME physiology scaled score $=10.423+0.417 \times$ class attendance $(\%)$. Hence, according to regression model equation, a student is expected to have $94.9 \%$ of class attendance to achieve a scaled score of 50, which is the national average in physiology NBME subject examination (Figure 1). 


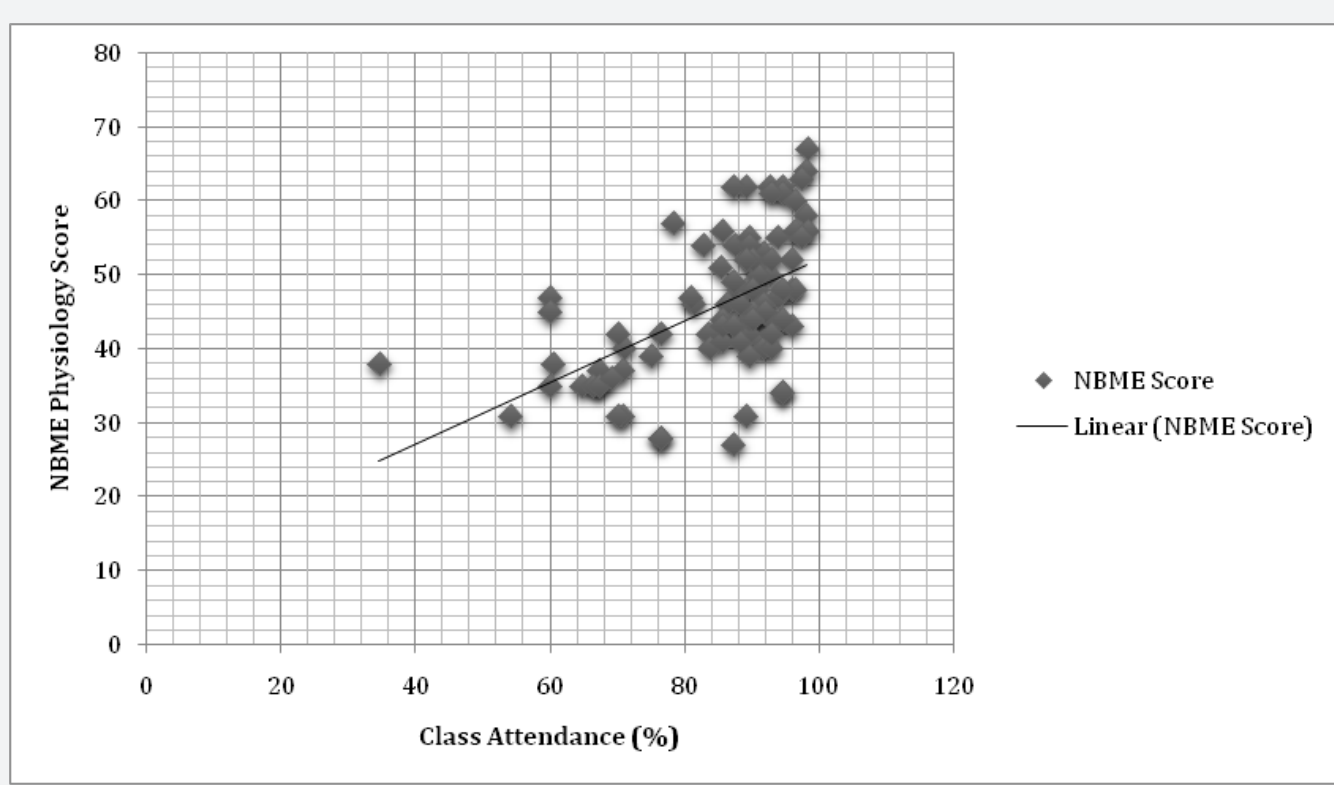

Figure 1: Rendering based on isosurface.

\section{Discussion}

The principal result of our study was a significant positive correlation between the class attendance (\%) and NBME physiology scaled score $(\mathrm{r}=.543, \mathrm{p}<0.001)$. The result of our study is in line with the meta-analytical review done by Crede et al. [2] who found a strong relationship between the class attendance and college grades. Hence, they suggested increasing class attendance rates among college students to achieve dramatic improvements in average grades [2]. In a study of relationship between class attendance and NBME part I examination done by Fogleman et al. [4] analysed the results of survey via a 2 X 2 chi-square for each item and scores on the NBME examination. It showed that only class attendance were significantly different between students scoring above the mean (511.2) and those below the mean on the NBME part I examination (chi-square $=4.766$; $\mathrm{p}<0.05$ ) [4].

Similarly, Hammnen et al. [7] indicated a negative correlation between grades and number of absences from class. However, their correlation was weak, indicating that other factors were involved as most of the studies, including theirs, did not have matched experimental and control groups. Hence, it is impossible to state whether regular attendance caused slightly higher scores or whether the better students attend the classes more frequently [7]. Millis et al. [8] demonstrated that a significant correlation $(r=0.203, \mathrm{P}<0.05)$ between the attendance and students' grade averages at the end of their second year. They found increased grade averages as attendance increased. Students may assume that the self-directed study and distance learning are equivalent to the class activities. The risk of poor performance in a significant number of first-year medical students may be because of their belief that the internet- and classroom-based instructions in basic medical science courses are equivalent [8].

In a study done by Subramaniam et al. [9] in a medical college, they found a significant correlation between the attendance and the students who passed the University examinations. The number of students passing the examination was maximum ( $>90 \%$ ) compared to those getting distinction and failing the exam after they made attendance mandatory for the medical course [9]. A moderate to strong negative correlation between absenteeism and academic achievement suggested that the class attendance is very critical for learning and important in improving the knowledge and academic achievement [10]. Bamuhair et al. [11] reported the positive effect of attendance on the academic performances with a stronger effect for lectures compared to other teaching modalities. They suggested that the lecture attendance is critical for learning even in nontraditional methods of education [11].

In a study of association between lecture attendance and grade outcomes done by Horton et al. [12] they reported the positive correlation of exam grades with the lecture attendance in male students $(\mathrm{r}=0.29, \mathrm{P}<0.04)$ and overall $(\mathrm{r}=0.21, \mathrm{P}<$ 0.02 ) but not for female students considered separately ( $r=0.10$, NS). They also found that the overall grades were correlated positively with lecture attendance in male students $(\mathrm{r}=0.35, \mathrm{P}$ $<0.01)$ and overall $(\mathrm{r}=0.31, \mathrm{P}<0.001)$ but not when female students were considered separately $(r=0.20$, NS) [12].

However, Cohall et al. [13] in their study found no significant association between the improvement in attendance and improved academic performances in the examinations. Their findings suggested that the other factors are more critical to 
academic success [13]. Therefore, even though the present study suggests that the higher percentage of class attendance add value to academic performance in board examinations, the other factors such as quality of lectures and the study habits may also have an equal impact in academic performance of the students in board examinations.

\section{Conclusion}

According to our study, the physiology class attendance (\%) has a strong positive correlation with the scaled score in physiology NBME subject examination. It means that the performance of students in physiology NBME subject examination improves with increase in their class attendance (\%). Therefore, we recommend that the faculty members should encourage the students to attend the classes regularly by implementing incentives such as points for class attendance or by applying academic activities during the class such as discussing comprehensive questions at the end of the lecture. Implementation of class attendance policies might enhance the performance of medical students in board examinations too.

We conducted this study only in the subject of Physiology. The study that includes a larger sample size from multiple basic medical science subjects and study samples from more than one medical school might further strengthen the results. Further studies should address the quality of lectures, other ways to increase intrinsic motivation for attending lectures, whether the relationship is causal, and whether the improvement in attendance percentage can improve the NBME physiology performances. In addition, the impacts of other factors such as study habit, environment, cultural habit, gender difference, and personal, familial, and socioeconomic stresses need to be assessed in further studies.

\section{References}

1. Crede M, Kuncel NR (2008) Study habits, skills, and attitudes: The third pillar supporting collegiate academic performance. Perspect Psychol Sci 3(6): 425-453.
2. Crede M, Roch SG, Kieszczynka UM (2010) Class attendance in College: A meta-analytic review of the relationship of class attendance with grades and student characteristics. Review of Educational Research 80(2): 272-295.

3. National Board of Medical Examiners (2016) NBME Subject Examinations.

4. Fogleman BS, Cleghorn GD (1983) Relationship between class attendance and NBME Part I examination. J Med Educ 58(11): 904.

5. Kozar RA, Kao LS, Miler CC, Schenarts KD (2007) Preclinical predictors of Surgery NBME exam performance. J Surg Res 140(2): 204-207.

6. Pangaro LN, McGaghie WC (2015) The use of pre-matriculation data. Medical Student Evaluation and Assessment ( $2^{\text {nd }}$ edn), Gegendatz Press, New York, USA, pp 50-51.

7. Hammen CS, Kelland JL (1994) Attendance and grades in a human physiology course. Am J Physiol 267(6 pt 3): S105-S108.

8. Millis RM, Dyson S, Cannon D (2009) Association of classroom participation and examination performance in a first-year medical school course. Adv Physiol Educ 33(3): 139-143.

9. Subramaniam BS, Hande S, Kommatil R (2013) Attendance and achievement in medicine: investigating the impact of attendance policies on academic performance of medical students. Ann Med Health Sci Res 3(2): 202-205.

10. AbduRuz ME (2015) Does excessive absence from class lead to lower levels of academic achievement? European Scientific Journal 11(7): 1857-1881.

11. Bamuhair SS, Farhan ALA, Althubaiti A, Rahman S, Al-Kadri HM (2016) Class attendance and cardiology examination: a study in problembased medical curriculum. Int J Gen Med 9: 1-5.

12. Horton DM, Wiederman SD, Saint DA (2012) Assessment outcome is weakly correlated with lecture attendance: influence of learning style and use of alternative materials. Adv Physiol Educ 36(2): 108-115.

13. Cohall DH, Skeete D (2012) The impact of an attendance policy on the academic performance of first year medical students taking the Fundamentals of Disease and Treatment course. Caribbean Teaching Scholar 2(2): 115-123.

\section{Your next submission with Juniper Publishers} will reach you the below assets

- Quality Editorial service

- Swift Peer Review

- Reprints availability

- E-prints Service

- Manuscript Podcast for convenient understanding

- Global attainment for your research

- Manuscript accessibility in different formats ( Pdf, E-pub, Full Text, Audio)

- Unceasing customer service

Track the below URL for one-step submission

https://juniperpublishers.com/online-submission.php 